Article

\title{
Prioritization of Drugs for Fungal Keratitis Eye Infections: An In-Silico Analysis
}

\author{
Punitha Thambidurai ${ }^{1}$, Vinodhini Raja ${ }^{2}$, Saranya Ashokapuram Selvam ${ }^{3}$, \\ Moorthy Kannaiyan ${ }^{3, *}$ and Gnanendra Shanmugam ${ }^{4, *}$ \\ 1 Department of Microbiology, SAN International College of Arts and Science, Mavuthampathy Village, \\ Navakkari, Coimbatore, Tamilnadu 641105, India; punithat79@gmail.com \\ 2 Department of Microbiology, Shri Sakthikailassh Women's College, Military Road, Ammapet, Salem, \\ Tamilnadu 636003, India; rvinodhini71@gmail.com \\ 3 Department of Microbiology, Vivekanandha College of Arts and Sciences (W), Elayamplayam, Tiruchengode, \\ Namakkal dist, Tamilnadu 637205, India; saranyaselvam.as@gmail.com \\ 4 Microbial Genomics Lab, Department of Biotechnology, College of Life and Applied Sciences, \\ Yeungnam University, Gyeongbuk, Gyeongsan 38541, Korea \\ * Correspondence: abbaikannamoorthy@gmail.com (M.K.); gnani@ynu.ac.kr (G.S.); \\ Tel.: +91-9442545967 (M.K.); +82-10-5609-2678 (G.S.)
}

Received: 23 April 2019; Accepted: 12 June 2019; Published: 18 June 2019

check for updates

\begin{abstract}
The fungal keratitis (FK) infections that cause cornea inflammations are more virulent than other bacterial keratitis infections and remain one of the most ethereal and challenging infections for ophthalmologists to diagnose and treat. Thus, the urgency in understanding the current perspectives of antifungal agents and their interactions with novel therapeutic targets and the identification of novel anti-fungal agents are at the frontline of studies in the pharmaceutical industry. In this study, DNA dependent RNA polymerase was modelled and virtually screened against eight antifungal agents, and it was found that Itraconazole $(-22.0427 \mathrm{~kJ} / \mathrm{mol})$, Ketoconazole $(-20.2194 \mathrm{~kJ} / \mathrm{mol})$, and Voriconazole $(-12.6388 \mathrm{~kJ} / \mathrm{mol})$ exhibited better binding interactions. further, the structural and electronic properties of Itraconazole calculated through density functional theory studies revealed the sites of chemical reactivity that are vital in the compounds for possible interactions with RNA polymerase (RNAP). Hence, this study explores the binding efficacies of various anti-fungal agents through docking studies and their chemical entities, which might pave a significant path for the design of novel anti-fungal agents against hyalohyphomycetes causing keratitis.
\end{abstract}

Keywords: fungal keratitis; hyalohyphomycetes; Aspergillus flavus; Aspergillus fumigatus; docking; density functional theory (DFT)

\section{Introduction}

Cornea inflammations caused by fungal infections (fungal keratitis or keratomycosis) remain one of the most ethereal and challenging infections for ophthalmologists to diagnose and treat [1]. These fungal keratitis (FK) infections are more likely to perforate the cornea and more virulent than other bacterial keratitis infections [2]. Many cases of ocular trauma are reported as major predisposing factors of fungal keratitis infections in developing countries, including India and Ghana [3]. The incidence of fungal keratitis has been reported to range between $25.6 \%$ and $36.7 \%$ in various parts of India [4-6]. FK infections are believed to usually occur in the population engaged in agricultural or outdoor work where the fungal conidia of plant or animal origin, including dust particles, might directly lodge in the corneal stroma and allow exogenous fungi invasions [7].

It is evident that species of filamentous fungi, such as Aspergillus and Fusarium, are most commonly associated with keratitis in tropical countries, including India [8,9]. Aspergillus is a very large genus, 
including more than 185 species, to which humans are frequently exposed. Certain Aspergillus species, mainly A. flavus, A. fumigatus, A. terreus and A. niger, have long been regarded as important pathogens in eye infections, especially keratitis [10]. Aspergillus strains are among the most frequent organisms that cause fungal keratitis among rural agricultural workers. Recent molecular studies revealed that the spectrum of Aspergillus species capable of causing mycotic keratitis is much wider than earlier believed, including A. tamarii [11], A. nomius [12], A. tubingensis [13] and A. brasiliensis [14].

The major groups of antifungal drugs are azoles and polyenes, which are fungistatic with interference in protein synthesis and fungicidal with an effect on cell wall function, which has been accepted for the treatment of keratitis $[15,16]$; however, their efficacies are limited for several reasons, including the increasing resistance to antifungal drugs, their limited effect on certain fungal species, and their exclusively topical route of administration, which limits the use of those drugs to treat the superficial fungal infections, as opposed to deep fungal invasions [17]. The presence of deep fungal lesions and invasions may necessitate a systemic route of administration, such as intravenous or oral administration. Further, the emergence of resistance and a high blindness rate in keratitis warrants a careful consideration and selection of anti-fungal agents, the identification of novel therapeutic drug targets, or the design of novel anti-fungal agents for better therapy. The inhibition of fungal RNA synthesis might also exert antifungal effects through a reduction in subsequent protein synthesis. Indeed, the agent flucytosine exerts its antifungal effects at least partly through inhibition of RNA synthesis, suggesting that this target might be exploited for anti-fungal therapy [18]. A few in-vitro studies [19-22] have reported that a combination of amphotericin B and rifampin, an antibacterial agent that inhibits RNA polymerase, synergistically interacts against a variety of fungi. In line with this result, the DNA dependent RNA polymerase (RNAP) that is responsible for transcribing DNA has been considered as a direct or indirect target for the treatment of various fungal infections, including fungal keratitis [23]. In last few decades, structure based virtual screening has become prominent in drug discovery, particularly in molecular docking studies [24].

Thus, in the present study, polyenes and azoles were selected for their molecular docking and better binding affinities against RNAP from hyalohyphomycetes causing keratisis. Namely, A. flavus and A. fumigatus, are explored. Also, the structural and electronic properties of the best docked compound were calculated through DFT (density functional theory) studies to explore the sites of chemical reactivity on the compounds that are vital for possible interactions with RNAP. Hence, this study explores the binding efficacies of various anti-fungal agents through docking studies, and their chemical entities might pave a significant path for the design of novel anti-fungal agents against hyalohyphomycetes causing keratitis.

\section{Result and Discussion}

Fungal keratitis (FK) infections are more virulent than other bacterial keratitis infections. The urgency in understanding the current perspectives of antifungal agents and their interactions with novel therapeutic targets, along with the identification of novel anti-fungal agents, are at frontline of studies in the pharmaceutical industry. Recently, with the advent of higher computational strategies, structural based drug design (SBDD) has assumed a large role in the identification and development of promising novel compounds by many pharmaceutical researchers [24]. In the last few decades, many research groups have suggested the usage of SBDD, especially molecular docking methods, as a prospective method to screen potential novel compounds against many diseases [25]. In the present study, the binding efficiencies of eight anti-fungal compounds against RNAP from keratitis causing hyalohyphomycete, A. flavus, and A. fumigatus, are explored through docking studies, and the chemical stability of the best docked Itraconazole is explored through DFT studies.

\subsection{Target-Template Alignment for Homology Modeling}

The RNAP protein sequence of A. flavus and A. fumigatus was used as the target sequence, and a similarity search was performed against the protein databank (PDB) for a suitable template by 
using Basic Local Alignment Search Tool for Protein (BLASTP). The obtained X-ray crystal structures were considered as templates and were further analyzed for their resolution, sequence similarity, and secondary structure similarity (SOPMA), covering the maximum range of the target sequence. The X-ray crystal structures from the PDB database, the 3h0g_B chain, shared a sequence similarity of $63.64 \%$ and $67.80 \%$ with the RNAP from A. flavus and A. fumigatus, respectively. Previous studies demonstrated that a sequence identity higher than $25 \%$ between the two proteins is similar in $3 \mathrm{D}$ structures [26]. Hence, the 3D structures of the respective template were considered to be suitable for modeling through homology modeling.

\subsection{Homology Modeling}

The template-target sequence alignment files were used to generate a bundle of five initial models of RNAP from A. flavus and A. fumigatus by applying spatial restraints from the initial structures of the templates in the automated homology modeling tool, Modeler9v9. The Discrete Optimized Protein Energy (DOPE) score significantly reveals the structural compatibility of the models considered to rank the models. Model-2 (RNAP- A. flavus) (Figure 1a) and model-1 (RNAP- A. fumigatus) (Figure 2a), with the lowest DOPE assessment score, were selected as the best models with the most stable minimized energy and thus considered for further analysis.

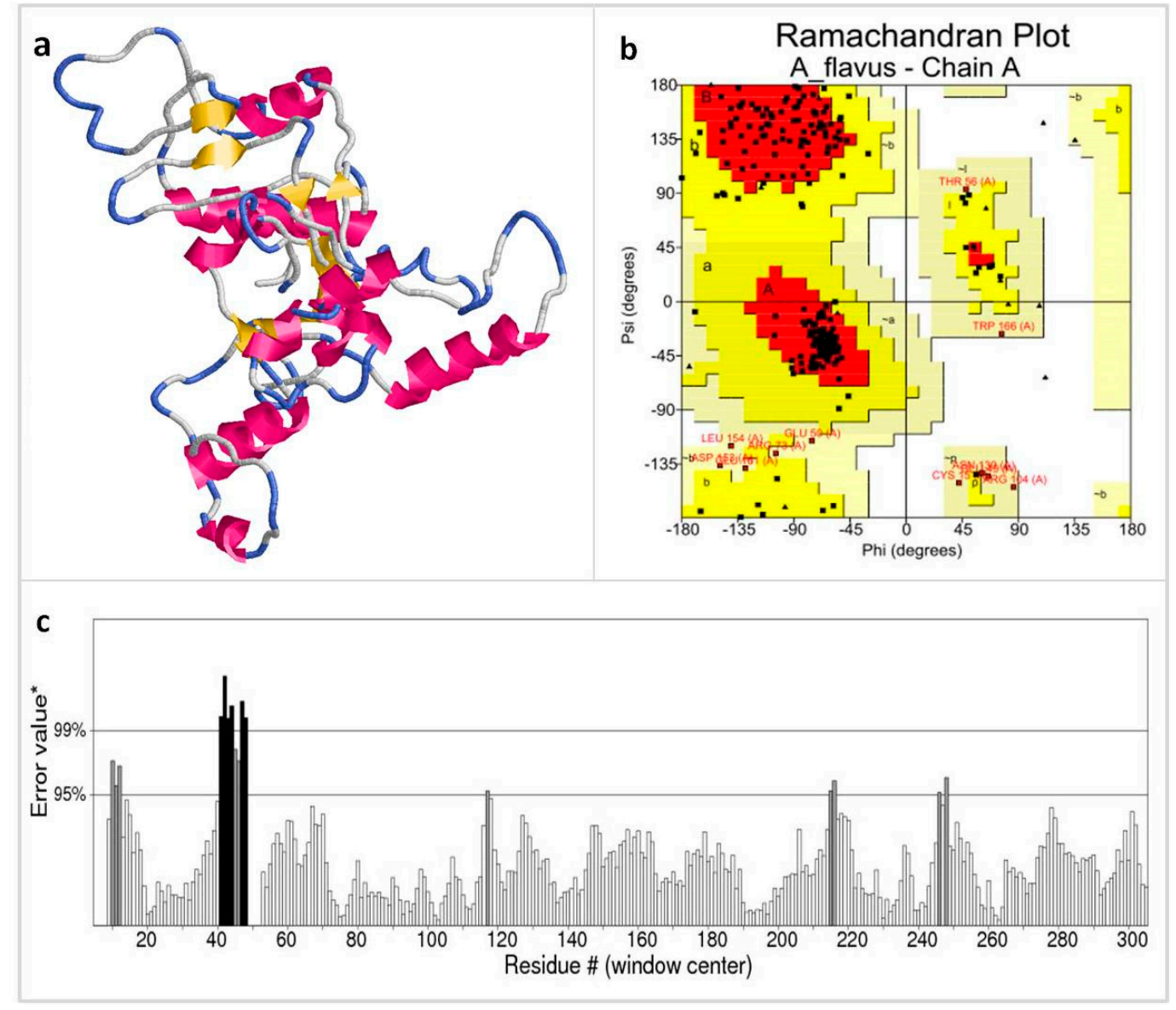

Figure 1. Theoretical model of the RNA polymerase (RNAP) structure from Aspergillus flavus and model validation through the Structural Analysis and Verification Server (SAVES) server. (a) The 3D structure of the built protein in a cartoon representation with the following structure colors: Pink (helices), Yellow (sheets), and blue (loop); (b) model validation by a Ramachandran plot; (c) ERRAT Plot showing the generated model at a good high resolution, as the regions of the modeled structure that can be rejected at $95 \%$ and $99 \%$ confidence is very low. 


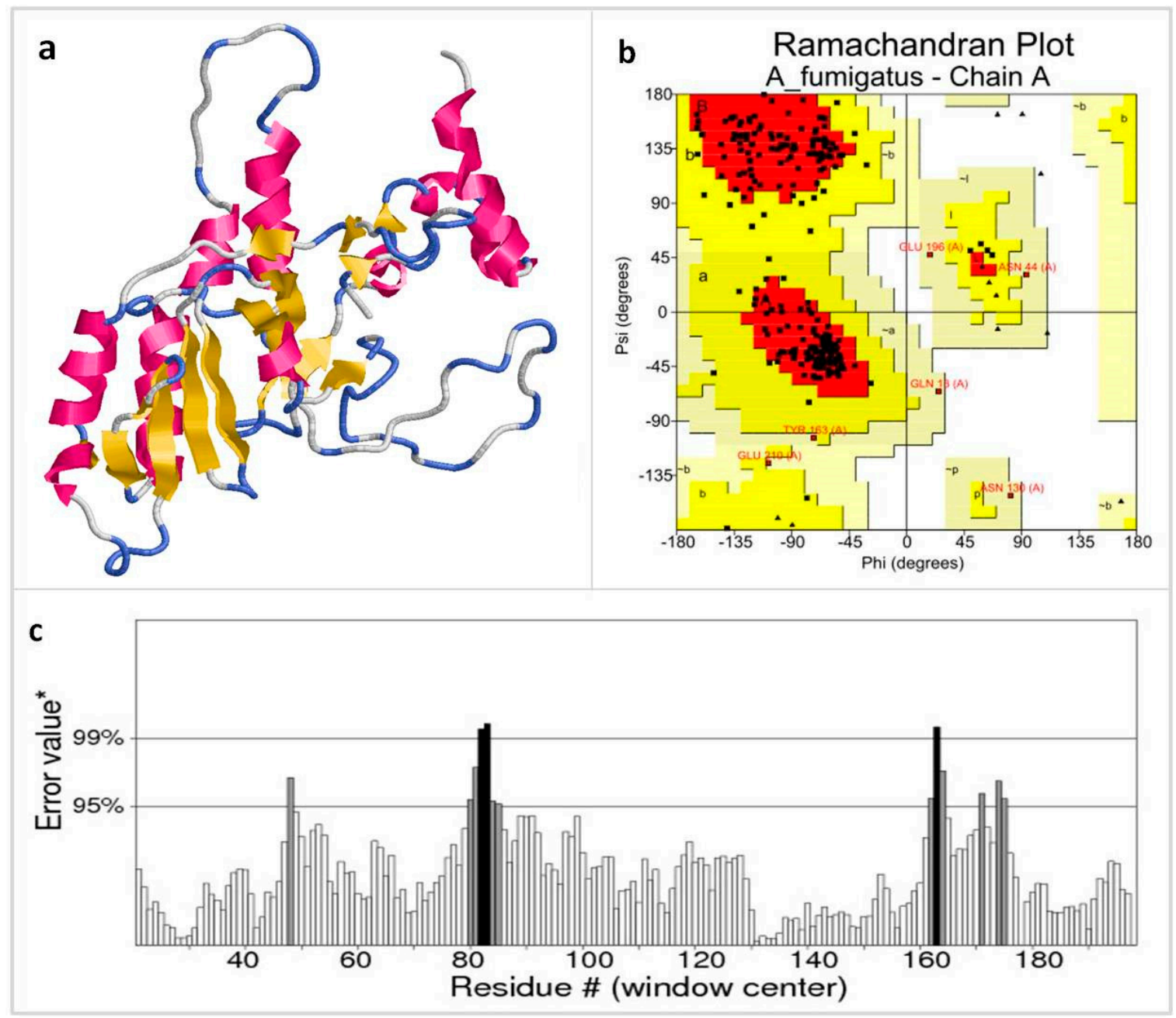

Figure 2. Theoretical model of the RNAP structure from Aspergillus fumigatus and model validation through the SAVES server. (a) The 3D structure of the built protein in a cartoon representation with the following structure colors: Pink (helices), Yellow (sheets), and blue (loop); (b) model validation by a Ramachandran plot; (c) ERRAT Plot showing the generated model at a good high resolution, as the regions of the modeled structure that can be rejected at $95 \%$ and $99 \%$ confidence is very low.

\subsection{Model Validation}

The quality of the modelled structures was assessed through online quality evaluation tools such as PROCHECK, ERRAT, and Verify 3D, provided through the Structural Analysis and Verification Server (SAVES) of UCLA-DOE Lab. The phi and psi angles that explore the stereo-chemical parameters of the energy-minimized models were determined by using PROCHECK; the 1D-3D structure compatibility of the best models were determined by Verify 3D, and the regions of the modelled structure that can be rejected at $95 \%$ and $99 \%$ confidence intervals, were predicted through ERRAT programs. In general, $>85 \%$ of residues in modelled structures that fall under the most favored regions of the RC plot are considered suitable for further study. Verify 3D calculates the amino acid propensity of each residue of the model with comparison to the PDB structures, and reveals the final score as a sum of the propensities of the individual residues in the built model $[27,28]$. Usually, the ERRAT scores are expressed as a percentage. The ERRAT scores of $>95 \%$ were graded for high resolution structures, while low-resolution structures were graded at approximately $91 \%$.

The Ramachandran plot (PROCHECK) of the energy-minimized models of RNAP from A. flavus (Figure 1b) and A. fumigatus (Figure 2b) exhibited most of the residues in the most favorable region and $1.3 \%$ and $1.7 \%$ in the disallowed region, whereas the Ramachandran plot (RC plot) of the template 
( $3 \mathrm{~h} 0 \mathrm{~g} \_\mathrm{B}$ chain) exhibited $4.6 \%$ residues in the disallowed regions and $59.2 \%$ in the most favored regions. Significantly, this revealed that the generated models of RNAP are best, as they exhibited a greater number of residues $(76.1 \%$ and $84.3 \%$ ) in the most favorable regions and a low number of residues in the disallowed region of the RC plot. Further, the ERRAT plot values of the modelled RNAP from A. flavus (Figure 1c) and A. fumigatus (Figure 2c), and the Verify 3D measured quality factor values, suggested that the built models are relevant, reliable, and of good quality (Table 1).

Table 1. Stereo-chemical parameters of the RNAP protein models and the template assessed at the SAVES server.

\begin{tabular}{ccccccc}
\hline \multirow{2}{*}{ Organism } & \multicolumn{9}{c}{ Procheck (Ramachandran Plot) } & \multirow{2}{*}{ Verify 3D } & \multirow{2}{*}{ ERRAT } \\
\cline { 2 - 5 } & MFR & AAR & GAR & DAR & & \\
\hline 3h0g_B chain & 59.2 & 27.2 & 8.5 & 4.6 & 77.43 & 81.908 \\
Aspergillus flavus & 76.1 & 16.2 & 6.4 & 1.3 & 91.34 & 86.953 \\
Aspergillus fumigatus & 84.3 & 11.1 & 3.0 & 1.7 & 77.92 & 79.395 \\
\hline
\end{tabular}

MFR: Most Favored Region; AAR: Additionally Allowed Region; GAR: Generously Allowed Region; DAR: Disallowed Region.

\subsection{Binding Site Prediction}

The quality of the modelled structures was assessed through online quality evaluation tools such as PROCHECK, ERRAT, and Verify 3D, provided through Structural Analysis and Verification Server (SAVES) of the UCLA-DOE Lab. The phi and psi angles that explore the stereo-chemical parameters of the energy-minimized models were determined by using PROCHECK; the 1D-3D structure compatibility of the best models were verified by Verify 3D, and the regions of the modelled structure that can be rejected at the $95 \%$ and $99 \%$ confidence intervals were predicted through the ERRAT programs. In general, $>85 \%$ of residues in the modelled structures that fall under the most favored regions of the RC plot are considered suitable for further study. Verify 3D calculates the amino acid propensity of each residue of the model compared to the PDB structures and reveals the final score as a sum of the propensities of the individual residues in the built model $[27,28]$. Usually, the ERRAT scores are expressed as a percentage. The ERRAT scores of $>95 \%$ were graded for high resolution structures, while low-resolution structures were graded at approximately $91 \%$.

The Ramachandran plot (PROCHECK) of the energy-minimized models of RNAP from A. flavus (Figure $1 b$ ) and A. fumigatus (Figure $2 b$ ) exhibited most of the residues in the most favorable region and $1.3 \%$ and $1.7 \%$ were in the disallowed region. whereas the Ramachandran plot (RC plot) of the template (3h0g_B chain) exhibited $4.6 \%$ residues in the disallowed regions and $59.2 \%$ in the most favored regions. Significantly, this revealed that the generated models of the RNAP are best, as they exhibited a greater number of residues $(76.1 \%$ and $84.3 \%)$ in the most favorable regions and a low number of residues in the disallowed region of the RC plot. Further, the ERRAT plot values of the modelled RNAP from A. flavus (Figure 1c) and A. fumigatus (Figure 2c), and the Verify 3D measured quality factor values, suggested that the built models are relevant, reliable, and of good quality (Table 2).

Table 2. Predicted binding pockets of the RNAP protein model from the DoGSite Scorer.

\begin{tabular}{cccccccc}
\hline Organism & $\begin{array}{c}\text { No. of Predicted } \\
\text { Pockets }\end{array}$ & $\begin{array}{c}\text { Best } \\
\text { Pocket }\end{array}$ & $\begin{array}{c}\text { Volume } \\
\left(\AA^{\mathbf{3}}\right)\end{array}$ & $\begin{array}{c}\text { Surface } \\
\left(\AA^{\mathbf{2}}\right)\end{array}$ & $\begin{array}{c}\text { Lipo Surface } \\
\left(\AA^{2}\right)\end{array}$ & $\begin{array}{c}\text { Depth } \\
(\AA)\end{array}$ & $\begin{array}{c}\text { Drug } \\
\text { Score }\end{array}$ \\
\hline $\begin{array}{c}\text { Aspergillus flavus } \\
\text { Aspergillus fumigatus }\end{array}$ & 14 & $\mathrm{P} 1$ & 809.02 & 1404.75 & 1192.41 & 21.04 & 0.84 \\
\hline
\end{tabular}

\subsection{Anti-Fungal Agents}

The 3D structures of eight anti-fungal agents, including Natamycin (CID_5281099), Ketoconazole (CID_456201), Voriconazole (CID_71616), Itraconazole (CID_55283), Miconazole (CID_4189), 
Fluconazole (CID_3365), Econazole (CID_3198), and Clotrimazole (CID: 2812), were retrieved in an SD file format from the pubchem database (Figure 3).

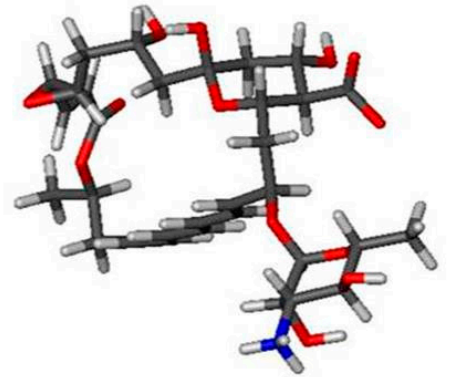

Natamycin

(CID_5281099)

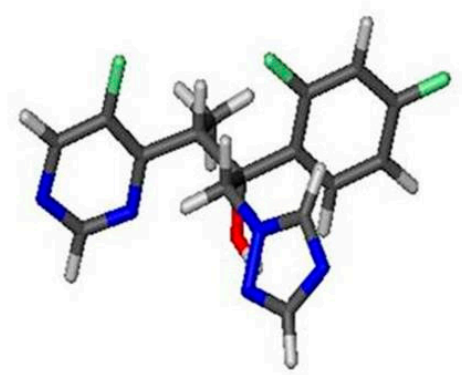

Voriconazole

(CID_71616)

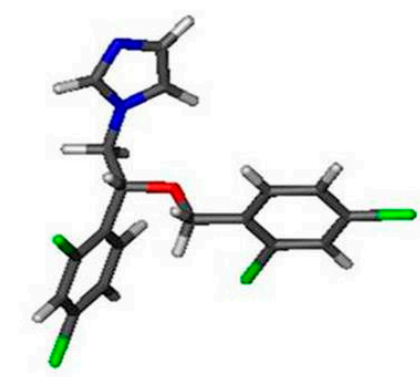

Miconazole

(CID_4189)

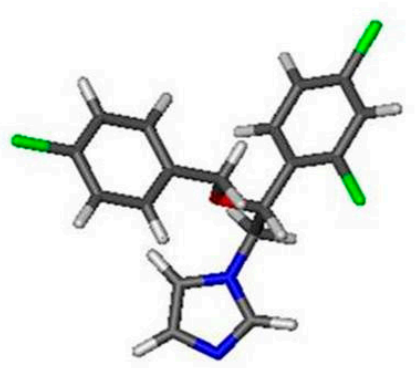

Econazole

(CID_3198)

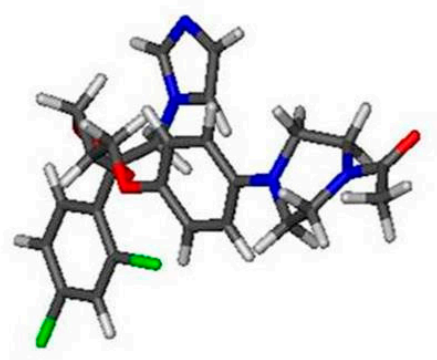

Ketoconazole

(CID_456201)

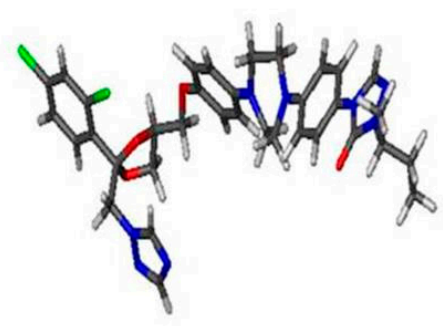

Itraconazole

(CID_55283)

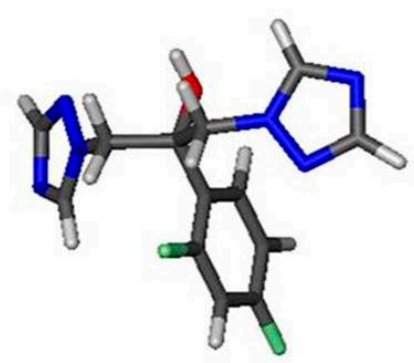

Fluconazole

(CID_3365)

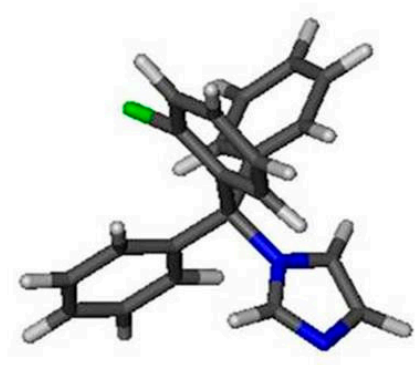

Clotrimazole

(CID: 2812)

Figure 3. The 3D structures of eight anti-fungal compounds, along with their pubchem IDs. 


\subsection{Docking Studies}

To explore the binding efficacy and the molecular basis of interactions, all eight compounds were docked within the predicted binding site of the RNAP targets from A. flavus and A. fumigates. From the docking results, it is evident that all the compounds exhibited binding energy against RNAP. Although all the compounds exhibited binding conformations in the active site pocket with both H-bond and non-bonded interaction, Itraconazole exhibited better interaction (based on binding energies) with RNAP in both $A$. flavus and A. fumigatus.

The clear understanding of the binding modes of Itraconazole within the binding site of the modelled structures can aid in the design of better fungal inhibitors against fungal keratitis. The binding interactions of these compounds with both the targets were stabilized with hydrogen bond and non-bond interactions. Generally, the non-bonded interaction made the protein-ligand complex more stable and established non-bonded force (vander waal's) to make the ligands achieve a stable conformation for better activity [29].

\subsection{Docking Interactions of Anti-Fungal Agents against Aspergillus Flavus}

Theoretically, all eight anti-fungal agents exhibited better binding efficiency with the modeled structure of RNAP from A. flavus (Table 3). The binding interactions supported by the formation of Hbond and the non-bonded interactions between the anti-fungal compounds and the predicted binding sites of RNAP are given in table along with their binding energies.

Table 3. Docking interactions of the anti-fungal agents within the binding pocket of the modeled RNAP from Aspergillus flavus.

\begin{tabular}{|c|c|c|c|c|c|c|c|}
\hline 5281099 & 456201 & 71616 & 55283 & 4189 & 3365 & 3198 & 2812 \\
\hline- & - & - & \#Ala76 & - & - & - & - \\
\hline- & - & - & \#His77 & - & - & - & - \\
\hline \#Val79 & - & \#Val79 & \#Val79 & - & - & - & \#Val79 \\
\hline- & - & - & \#Asn80 & - & - & - & - \\
\hline- & - & - & \#Thr81 & - & - & - & - \\
\hline Gln83* & - & \#Gln83* & - & - & - & \#Gln83 & Gln83* \\
\hline- & \#Arg87* & \#Arg87* & \#Arg87* & \#Arg87* & - & \#Arg87* & - \\
\hline- & \#Asn80 & & - & - & - & - & - \\
\hline \#Leu97 & - & \#Leu97 & - & - & - & - & \#Leu97 \\
\hline \#Arg99* & - & \#Arg99 & - & - & \#Arg99* & - & \#Arg99* \\
\hline- & - & - & - & - & \#Asp100* & - & - \\
\hline \#Ile101 & - & - & - & - & \#Ile101* & - & \#Ile101 \\
\hline- & - & - & - & - & \#Arg102* & - & - \\
\hline- & - & - & - & - & Glu103* & - & - \\
\hline- & \#Ile122 & \#Ile122 & \#Ile122* & \#Ile122 & - & \#Ile122* & - \\
\hline- & \#Asp123 & - & \#Asp123* & \#Asp123 & - & \#Asp123* & - \\
\hline- & \#Asn124* & Asn124* & - & \#Asn124* & - & - & - \\
\hline- & \#Asp125 & - & - & - & - & - & - \\
\hline Glu182* & - & - & - & - & - & - & Glu182* \\
\hline- & - & - & - & - & \#Glu184 & - & - \\
\hline
\end{tabular}


Table 3. Cont.

\begin{tabular}{cccccccc}
\hline 5281099 & 456201 & $\mathbf{7 1 6 1 6}$ & $\mathbf{5 5 2 8 3}$ & $\mathbf{4 1 8 9}$ & 3365 & 3198 & $\mathbf{2 8 1 2}$ \\
\hline \#Thr185 & - & \#Thr185 & - & - & \#Thr185 & - & \#Thr185 \\
\hline \#lle186 & - & \#Ile186 & - & - & - & \#Ile186 & \#Ile186 \\
\hline \#Met187 & - & - & - & - & - & - & \#Met187 \\
\hline \#Gly226 & - & - & - & - & - & - & \#Gly226 \\
\hline- & \#Thr228* & - & - & \#Thr228 & - & - & - \\
\hline- & \#Trp229 & - & - & \#Trp229 & - & - & - \\
\hline- & \#Thr230 & - & - & \#Thr230 & - & - & - \\
\hline- & - & \#His231 & \#His231 & \#His231 & - & \#His231 & - \\
\hline-18.8855 & -20.2194 & -14.1059 & -22.0427 & -12.4553 & -13.1749 & -10.8053 & -10.3426 \\
\hline
\end{tabular}

* Residues involved in H-bond interactions; \#* Residues involved in H-bond and non-bonded interactions. \# Residues involved in non-bonded interactions. Binding energies $(\mathrm{kJ} / \mathrm{mol})$ are provided in the last row.

It is observed that Itraconazole (CID_55283) exhibited the best binding interactions with a binding energy of $-22.0427 \mathrm{~kJ} / \mathrm{mol}$, followed by Ketoconazole $(-20.2194 \mathrm{~kJ} / \mathrm{mol})$ and Natamycin $(-18.8855 \mathrm{~kJ} / \mathrm{mol})$, and lastly, by the RNA from A. flavus (Figure 4a-c). The Itraconazole interaction is favored by the formation of Hbond with Arg87, Ile122, and Asp123, and hydrophobic interactions with Ala76, His77, Val79, Asn80, Thr81, Arg87, Ile122, Asp123, and His231. Whereas, the lowest dock score of $-10.3426 \mathrm{~kJ} / \mathrm{mol}$ is exhibited by Clotrimazole (2812) through the formation of Hbonds with Gln83, Arg99, Glu182, and non-bonded interactions with Val79, Leu97, Arg99, Ile 101, Thr185, Ile 186, Met187, and Gly226.

In the binding pocket of the modeled RNAP from A. flavus, the amino acids Arg87 and Ile122 were observed to play a vital role in establishing the Hbond and hydrophobic interactions with the compounds. The differences observed in the binding energies of the anti-fungal agents could significantly imply their in-vitro and in-vivo inhibition strategies. 
a

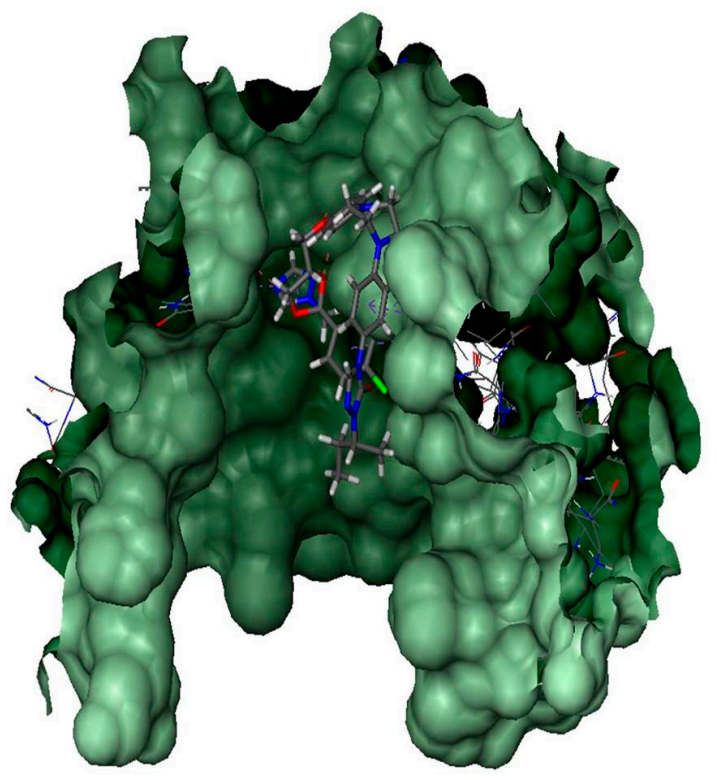

b

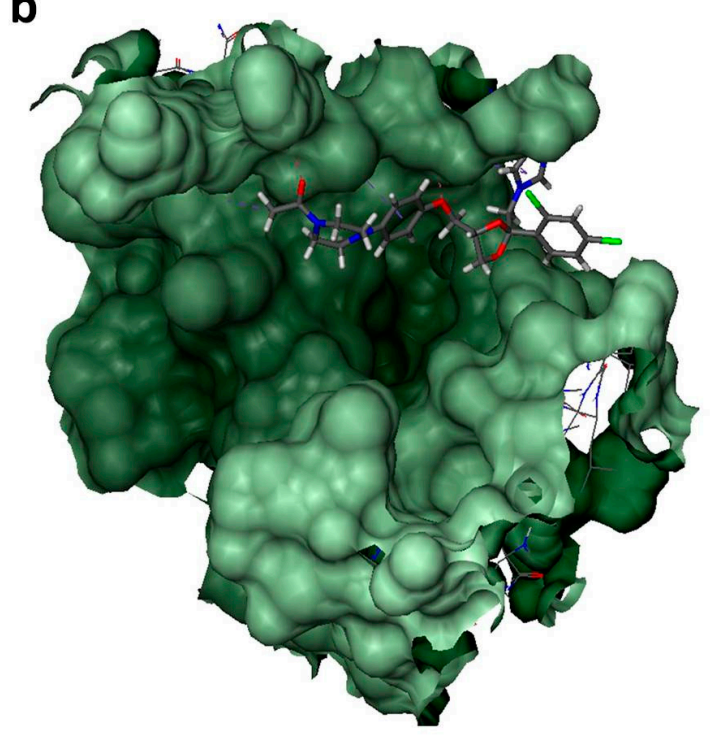

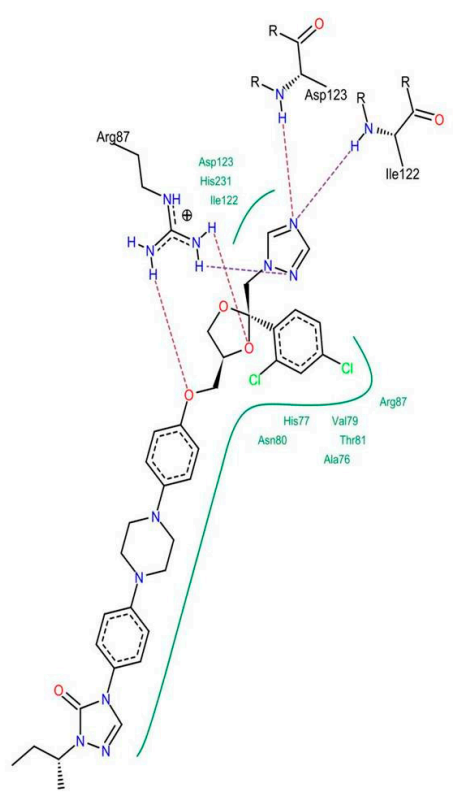

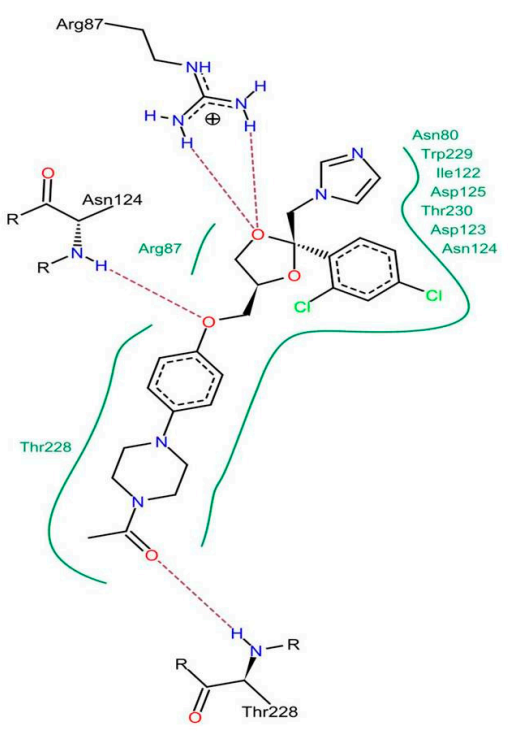

C
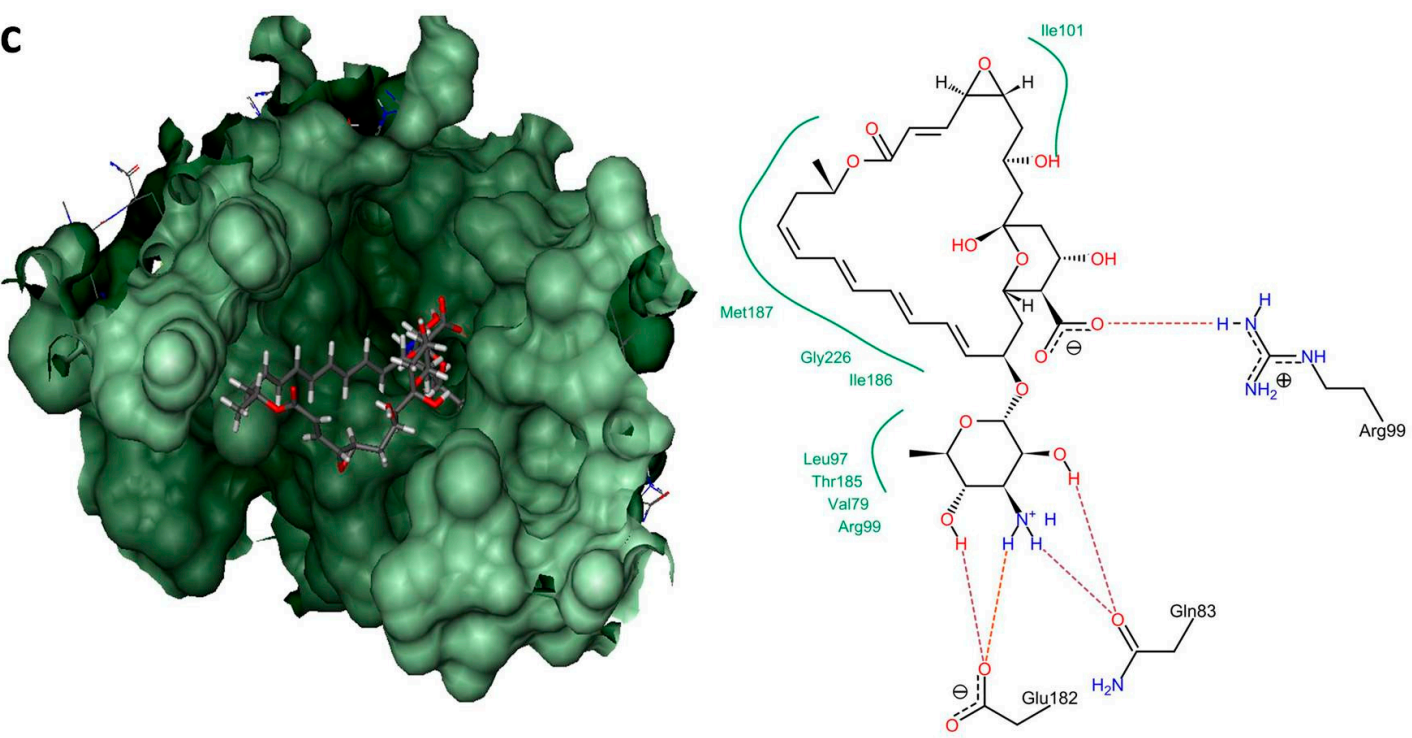

Figure 4. The docking complex and interactions of the best docked compounds with RNAP from A. flavus. (a) Itraconazole (Binding energy: $-22.0427 \mathrm{~kJ} / \mathrm{mol}$ ); (b) Ketoconazole (binding energy: 
$-20.2194 \mathrm{~kJ} / \mathrm{mol}$ ); (c) Natamycin (binding energy: $-18.8855 \mathrm{~kJ} / \mathrm{mol}$ ). The protein binding site in the docking complex is represented as a vandewaals surface, and the ligands are represented in a sticks model. The ligands in the interactions plot and the amino acids in the binding site favoring hbond interactions are shown in wireframe model. The docking complex and interaction plots were generated by using FlexX and the pose view modules of the LeadIT software, respectively.

\subsection{Docking Interactions of Anti-Fungal Agents against Aspergillus Fumigatus}

The best docking interaction score of $-13.7000 \mathrm{~kJ} / \mathrm{mol}$ was observed for Itraconazole (CID_55283), and is followed by Natamycin $(-12.8050 \mathrm{~kJ} / \mathrm{mol})$ and Voriconazole $(-12.6388 \mathrm{~kJ} / \mathrm{mol})$, and lastly, by the modeled RNAP from A. fumigatus (Figure $5 \mathrm{a}-\mathrm{c}$ ). The Itraconazole interaction was favored by the formation of Hbond with Ile27 and hydrophobic interactions with Leu21, Leu23, Met24, Cys25, Try26, Ile27, Val29, and Trp166. The lowest dock score of $-6.7883 \mathrm{~kJ} / \mathrm{mol}$ was exhibited by Econazole (CID_3198), where no Hbonds interactions were observed and non-bonded interactions were favored by Met24, Try26, Trp166, Try177, and Met237. It is evident that, theoretically, all the anti-fungal agents showed better binding with the modeled structure (Table 4) with narrow differences. It was observed that the amino acid Trp1, Val4, and Lys19 in the binding pocket of the modeled DNA dependent RNA polymerase II protein from A. fumigatus played a crucial role in exhibiting Hbond and hydrophobic interactions. The narrow differences in the binding energies of the compounds are attributed to in-vivo and in-vitro inhibition strategies.

Table 4. Docking interactions of anti-fungal agents within the binding pocket of the modeled DNA dependent RNA polymerase II protein from Aspergillus fumigatus.

\begin{tabular}{|c|c|c|c|c|c|c|c|}
\hline 5281099 & 456201 & 71616 & 55283 & 4189 & 3365 & 3198 & 2812 \\
\hline- & \#Trp1 & \#Trp1* & - & \#Trp1* & \#Trp1* & - & - \\
\hline- & - & Gly2* & - & Gly2* & Gly2* & - & - \\
\hline- & - & - & - & Leu3 & - & - & - \\
\hline \#Val4 & - & \#Val4* & - & \#Val4 & \#Val4* & - & - \\
\hline- & - & \#Cys5 & - & \#Cys5 & \#Cys5 & - & - \\
\hline- & - & \#Pro6 & - & \#Pro6 & \#Pro6 & - & - \\
\hline Glu8* & - & - & - & - & - & - & - \\
\hline \#Lys19 & - & \#Lys19 & - & \#Lys19 & \#Lys19 & - & - \\
\hline \#Asn20 & - & - & - & - & - & - & - \\
\hline \#Leu21* & - & - & \#Leu21 & - & - & - & - \\
\hline- & - & - & \#Leu23 & - & - & - & - \\
\hline- & - & - & \#Met24 & - & - & \#Met24 & - \\
\hline- & - & - & \#Cys25 & - & - & - & - \\
\hline- & - & - & \#Try26 & - & - & \#Try26 & \#Try26 \\
\hline- & - & - & \#Ile27* & - & - & - & - \\
\hline- & - & - & \#Val29 & - & - & - & - \\
\hline- & - & - & \#Trp166 & - & - & \#Trp166 & \#Trp166 \\
\hline- & - & - & - & - & - & \#Try177 & \#Try177 \\
\hline- & \#Ala180 & - & - & - & - & - & - \\
\hline- & \#Glu181 & - & - & - & - & - & - \\
\hline- & \#Glu183 & - & - & - & - & - & - \\
\hline
\end{tabular}


Table 4. Cont.

\begin{tabular}{cccccccc}
\hline 5281099 & 456201 & $\mathbf{7 1 6 1 6}$ & $\mathbf{5 5 2 8 3}$ & $\mathbf{4 1 8 9}$ & 3365 & 3198 & $\mathbf{2 8 1 2}$ \\
\hline- & \#Glu184 & - & - & - & - & - & - \\
\hline- & \#lle188 & - & - & - & - & - & - \\
\hline- & \#Met190 & - & - & - & - & - & - \\
\hline- & - & - & - & - & - & \#Met237 & - \\
\hline- & - & - & - & \#Ile238 & - & & - \\
\hline \#Val241* & - & - & - & - & - & - & - \\
\hline-12.8050 & -9.2480 & -12.6388 & -13.7000 & -10.1525 & -11.5391 & -6.7883 & -9.0994
\end{tabular}

* Residues involved in H-bond interactions; \#*Residues involved in H-bond and non-bonded interactions. \#Residues involved in non-bonded interactions. Binding energies $(\mathrm{kJ} / \mathrm{mol})$ are provided in the last row.

Thus the present docking studies suggest that Itraconazole, followed by the Ketoconazole and Voriconazole, might have significant in-vivo and in-vitro results against $A$, flavus and A. fumigatus. Further, this study implies that the presence of keto groups $(=\mathrm{O})$ on the Itraconazole and amide groups $(-\mathrm{N}=\mathrm{H})$ in the binding pocket of amino acids as electro negative elements are crucial for their interactions and for their anti-fungal activity. 

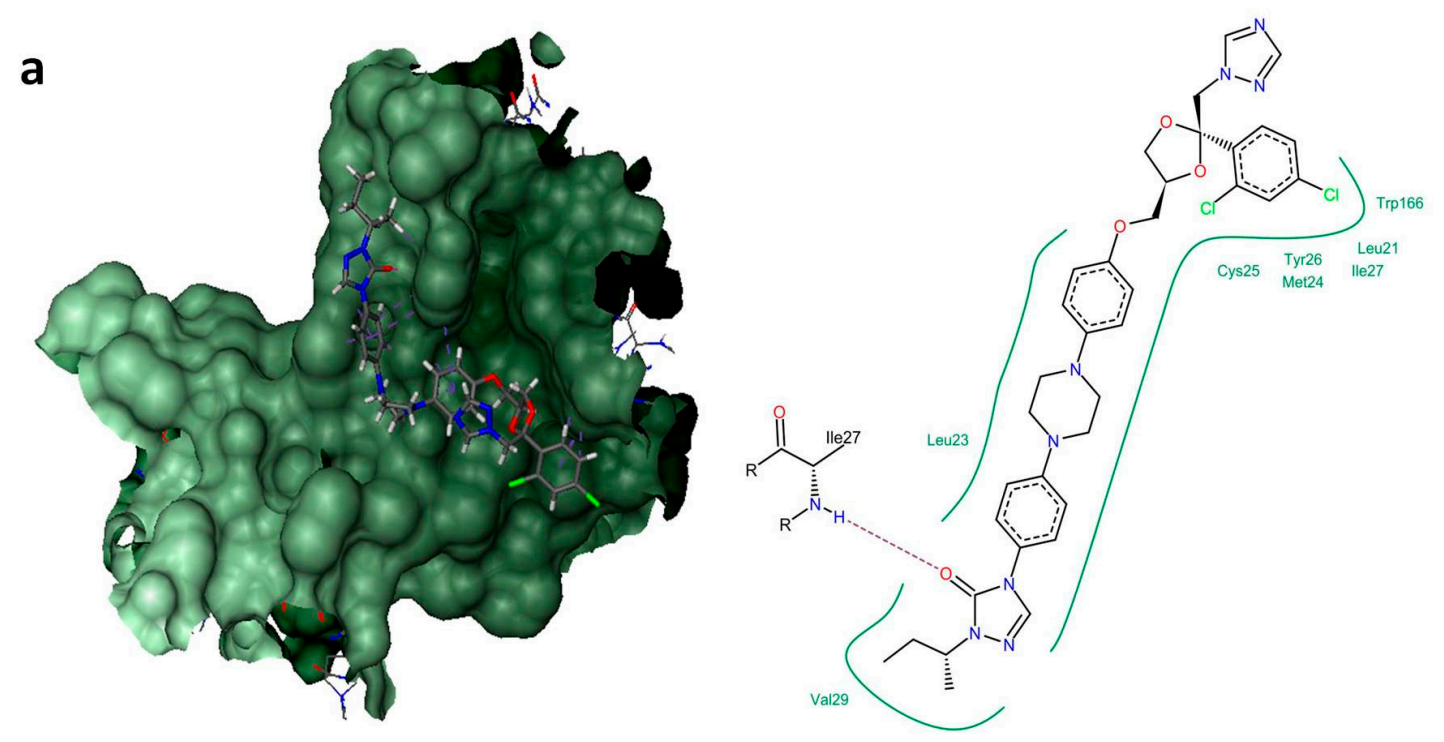

b
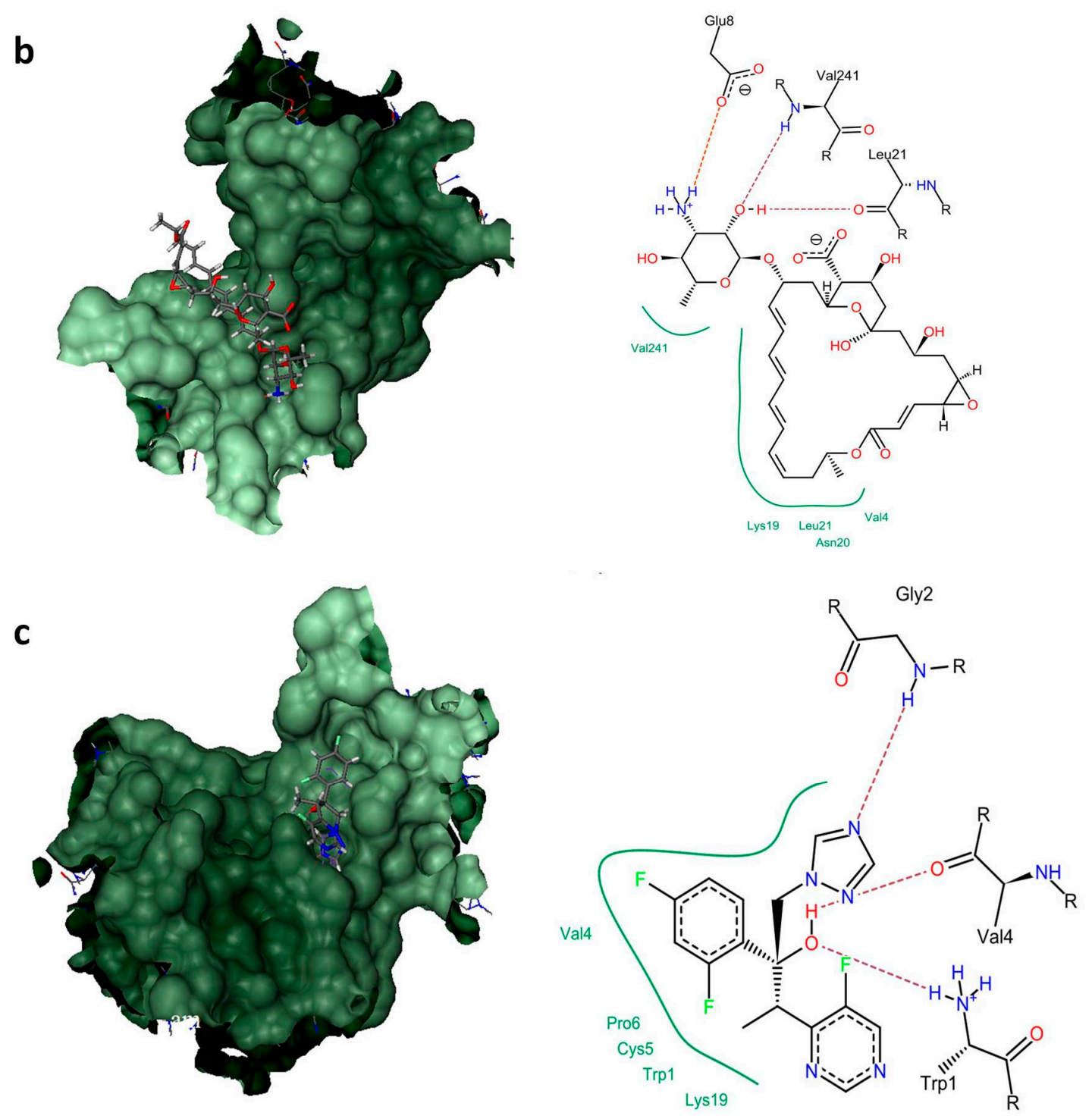

Figure 5. The docking complex and interactions of the best docked compounds with RNAP from $A$. fumigatus. (a) Itraconazole (Binding energy: $-13.7000 \mathrm{~kJ} / \mathrm{mol}$ ); (b) Natamycin (binding energy: 
$-12.8050 \mathrm{~kJ} / \mathrm{mol}$ ); (c) Voriconazole (binding energy: $-12.6388 \mathrm{~kJ} / \mathrm{mol}$ ). The protein binding site in the docking complex is represented as a vandewaals surface and the ligands are represented in a sticks model. The ligands in the interaction plot and the amino acids in the binding site favoring hbond interactions are shown in wireframe model. The docking complex and interactions plots are generated by using the FlexX and pose view modules of LeadIT software, respectively.

\subsection{In-Vitro Studies}

The inhibitory activities of the selected eight compounds on the fungal germination rate for A. flavus and A.fumigatus were determined by supplementing the fungal plate cultures with various concentrations of the compounds. It was observed that the germination rate of $A$. flavus significantly decreased from $80 \%$ to $30 \%$ with increased concentrations of Itraconazole from 0.125 to $2 \mu \mathrm{gg} / \mathrm{mL}$, respectively (Figure 6a). The inhibitory effect of Itraconazole is followed by Ketoconazole (35\% at $2 \mu \mathrm{gg} / \mathrm{mL})$ and Natamycin $(40 \%$ at $2 \mu \mathrm{gg} / \mathrm{mL})$. Similarly, the rate of germination of A. fumigatus was found to significantly decrease from $81 \%$ to $35 \%$ with increased concentrations of Itraconazole from 0.125 to $2 \mu \mathrm{gg} / \mathrm{mL}$, respectively (Figure $6 \mathrm{~b}$ ). The inhibitory effect of Itraconazole is followed by Natamycin $(40 \%$ at $2 \mu \mathrm{gg} / \mathrm{mL})$ and Voriconazole $(45 \%$ at $2 \mu \mathrm{gg} / \mathrm{mL})$. Evidently these results show that the in silico results are in accordance with the in vitro studies and that these drugs can be prioritized according to the types of fungus that cause fungal keratitis eye infections and also other infections caused by these fungal species. 


\section{a}

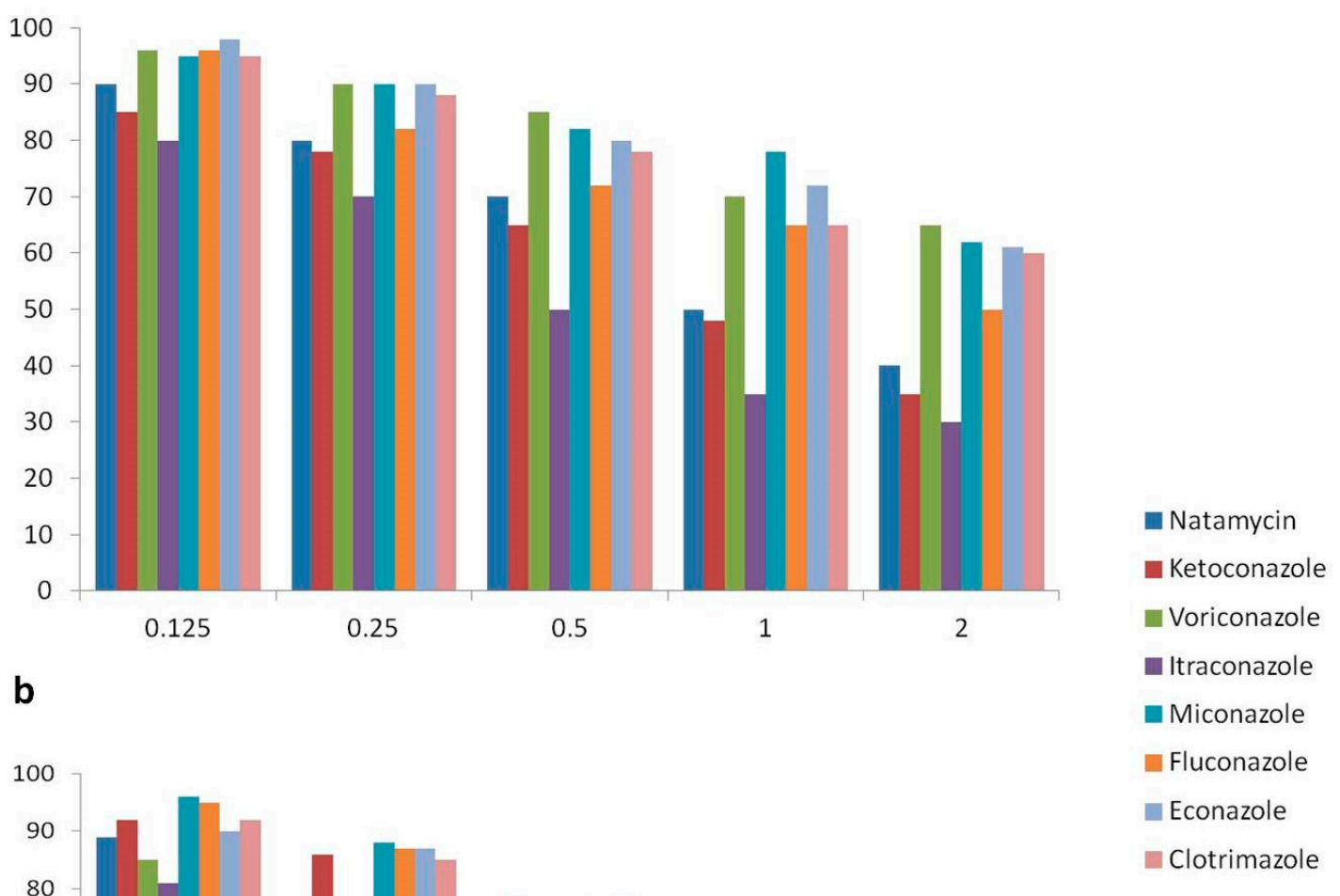

\section{b}

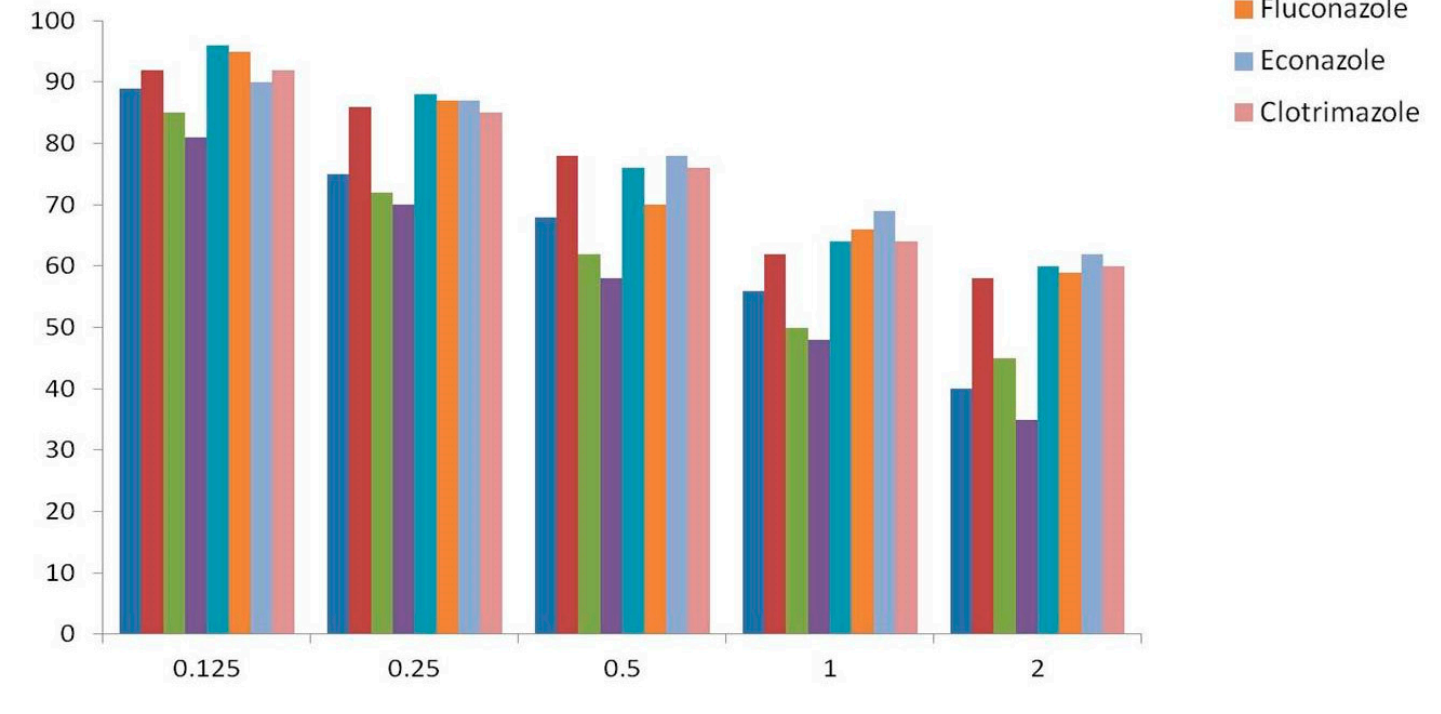

Figure 6. Inhibitory effects of the selected eight compounds on the rate of germination (\%); (a) Aspergillus flavus; (b) Aspergillus fumigatus.

\subsection{Density Functional Theory Analysis}

In general, DFT studies are quantum mechanical approaches that describe the accurate structural and electronic properties of compounds. The electronic distribution information provides a clear picture of protein-ligand interactions, and the inhibition potential of Itraconazole is computed by orbital energy calculations. The computed highest occupied molecular orbital (HOMO) and lowest unoccupied molecular orbital (LUMO) energies reveal the high and low electron density regions of the optimized Itraconazole geometries, as shown in Figure 7. The red and green color distributions represent the positive and negative phases in the molecular orbital wave function, respectively. The protein-ligand interaction stability is calculated inversely with the energy gap between the interacting orbital [30]. 

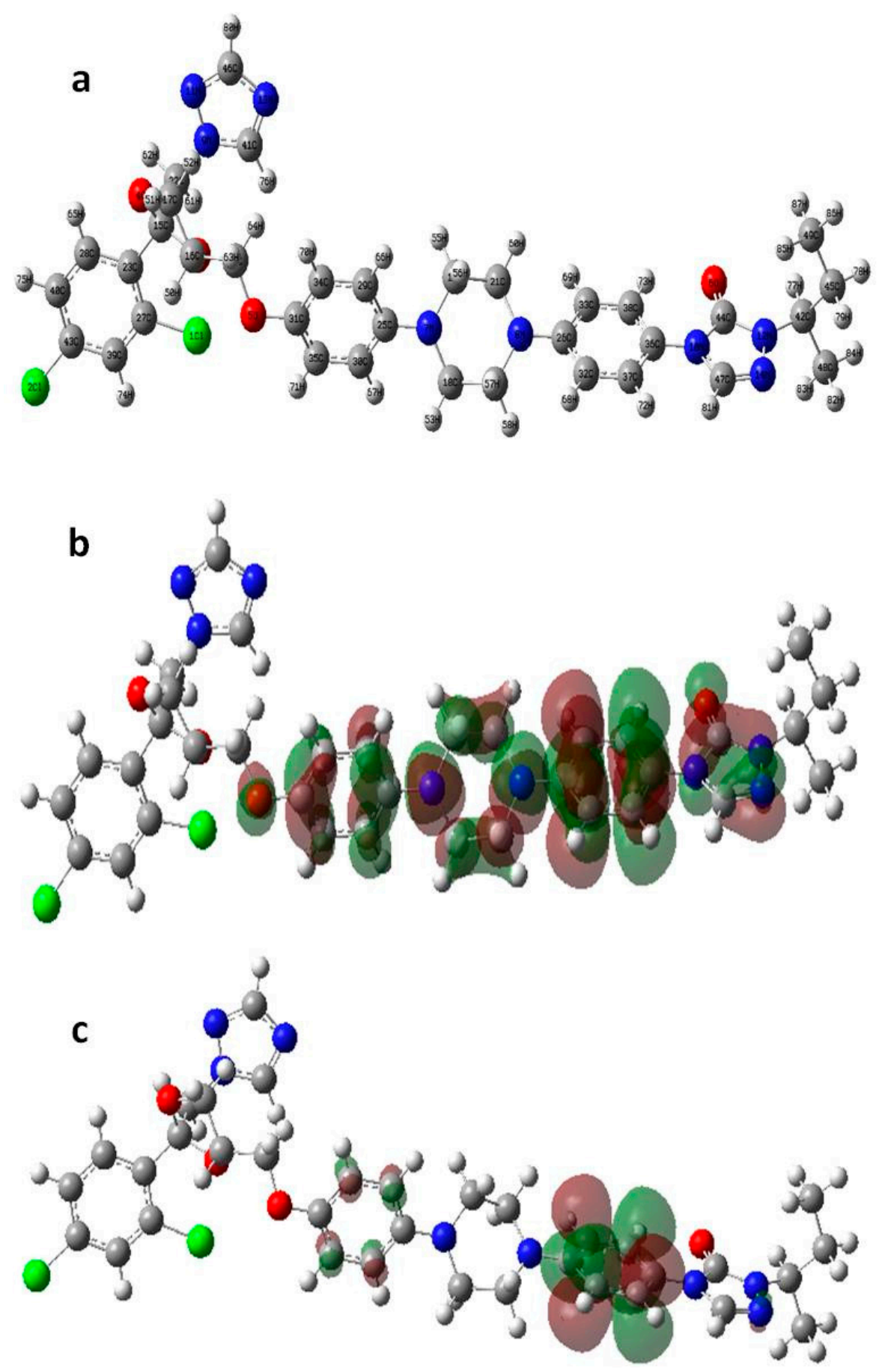

Figure 7. The highest occupied molecular orbital-lowest occupied molecular orbital (HOMO-LUMO) diagram of Itraconazole. (a) Optimized structure; (b) HOMO; (c) LUMO. The positive (red) and negative (green) phase distributions in the molecular orbital wave function. HOMO (electron donor regions) determines the ionization potentials. LUMO (electron acceptor regions) determines the electron affinity.

The increasing HOMO energy $(-3.7128 \mathrm{eV})$ and decreasing LUMO energy $(-3.8718 \mathrm{eV})$ in the compound implies an enhancement in complex interaction stability and, hence, suggests strong binding with the receptor. It is observed that the Itraconazole exhibited the energy. The larger the HOMO-LUMO energy gap, the harder, more stable, and less reactive the molecule [31]. The smaller the HOMO-LUMO energy gap, the softer, less stable, and more reactive the molecule. The LUMO-HOMO energy gap $(0.159 \mathrm{eV})$ reflects the chemical activity of the molecule. The decrease in 
the HOMO and LUMO energy gap explains the eventual charge transfer interaction taking place within the molecule due to the strong electron-accepting ability of the electron acceptor group. The strong charge transfer interaction is responsible for the bioactivity of the molecule. Thus, the DFT calculations performed here further substantiate our findings in molecular docking.

Thus, this study suggests that RNAP from A. flavus and A. fumigatus can be considered a prioritized drug target and that Itraconazole, Ketoconazole, and Voriconazole may play a pivotal role in the development of new, and urgently-needed, anti-fungal drugs against fungal keratitis infections. However, further in-vitro and in-vivo studies are required to ascertain the anti-fungal activity and potential toxic effects of Itraconazole as a specific and direct inhibitor of RNAP from A. flavus and A. fumigatus.

In conclusion, the 3D structures of the RNAP sequences of hyalohyphomycetes, such as A. flavus and A. fumigatus, that cause fungal keratitis were modelled through homology modelling. The binding efficacies of eight anti-fungal agents were tested for their prioritization against the modelled RNAP structures through molecular docking, and it was found that Itraconazole and Ketoconazole were effective against $A$. flavus, whereas Itraconazole and Voriconazole were active against $A$. fumigatus. Further, the chemical activity of Itraconazole was explored by computing the HOMO-LUMO energy gaps through DFT studies. The usage of Itraconazole might significantly show enhanced inhibition activity against RNA polymerase in fungus. Thus, Itracanazole could be used to treat the fungal diseases, including fungal keratisis, by targeting RNAP as an alternative drug target and overcoming drug resistance.

\section{Materials and Methods}

\subsection{Homology Modeling}

The DNA dependent RNA polymerase (RNAP) protein sequences from A. flavus (ACL99632.1) and A. fumigatus (ACL99633.1) were retrieved from the NCBI database [32]. The sequences were subjected to NCBI-BLASTP against the PDB database [33], and the 3D structure of RNA Polymerase II was obtained from Schizosaccharomyces pombe (PDBID:3h0g_Bchain) [34] as a potential template. By using the Modeller 9v9 [35], the 3D structures of RNAP from A. flavus and A. fumigatus were built as homologous models with reference to the potential template. For each target sequences, a total of five 3D models were built from the starting structure of the templates by satisfying the spatial restraints through random generation [36]. From the generated models, the best model was selected by considering the least root mean square deviation (RMSD) value in comparison with the template structure. For the selected best model, the energy was minimized through 20 steps of the steepest descent and a conjugate gradient by using the GROMOS [37] of the Swiss-PDB viewer [38]. Finally, an energy-minimized model was used for further analysis.

\subsection{Model Validation}

The quality of the generated 3D structures was evaluated by considering the stereo-chemical parameters of the homology models. The Phi and Psi angles representing the stereo-chemical parameters of the model, the compatibility of the generated 3D structures (with their own amino acid sequences), and the regions of the modeled structure that can be rejected with $95 \%$ and $99 \%$ confidence, were determined through PROCHECK [39], Verfiy3D [40], and ERRAT [41], respectively, at the SAVES server.

\subsection{Binding Pocket Prediction}

To predict the binding efficacies of the anti-fungal agents, the potential binding pocket with highest drug ability scores of modeled RNAP structures from A. flavus and A. fumigatus were determined by submitting the 3D structures to the DoGSite Scorer server [42]. 


\subsection{Molecular Docking}

The 3D structure of the selected anti-fungal agents, including Natamycin (CID_5281099), Ketoconazole (CID_456201), Voriconazole (CID_71616), Itraconazole (CID_55283), Miconazole (CID_4189), Fluconazole (CID_3365), Econazole (CID_3198), and Clotrimazole (CID_2812), were retrieved in the SDF formatfrom the Pubchem database [43]. The obtained compounds in the SDF format were virtually screened to reveal their binding efficiencies through docking in the predicted binding pockets of the modeled RNAP structures of fungi by using FlexX [44], with docking parameters such as triangle matching base placements, zero full score and No score contributions, and thresholds for full score and no score contributions of 30 and 70, respectively, clash handling values of $2.9 \mathrm{~A}^{03}$ and 0.6 for protein ligand clashes, with a maximum allowed overlap volume and intra-ligand clash factors, while considering the hydrogen in internal clash tests, and 200 as the default docking value for the maximum number of solutions per iteration and per fragmentation [45].

\subsection{Docking Interactions}

The docking interactions that illustrate the binding affinities of the anti-fungal agents with the predicted binding pockets of amino acids in the modeled RNAP from A. flavus and A. fumigatus were analyzed using the pose-view [46] module of LeadIT, which clearly picturized the Hbond and non-bond interactions.

\subsection{In Vitro Studies for Rate of Germination}

The mycelia of A. flavus and A. fumigatus were grown on corn meal agar (CMA) plates at $25^{\circ} \mathrm{C}$ for 8 days. The plates were unsealed and kept under light for conidiation. The conidia were suspended in distilled water containing various concentrations of eight antifungal compounds. Then, $40 \mu \mathrm{gL}$ of the mixture was placed on hydrophobic glass slides and incubated at $25^{\circ} \mathrm{C}$ for $8 \mathrm{~h}$ in a moistened box [47]. After incubation, the rate of germination was calculated both in the presence and absence of drugs.

\subsection{Density Functional Theory Study}

Density functional theory (DFT) calculations were performed on Itraconazole to determine the molecular energy gap between the highest occupied molecular orbital (HOMO) and the lowest unoccupied molecular orbital (LUMO) by using Gaussian $09 \mathrm{w}$ with B3LYP with 6-3IG** as a functional basic set [48].

Author Contributions: Conceptualization, P.T., V.R. and S.A.S.; Data curation, M.K. and G.S.; Formal analysis, M.K.; Investigation, P.T.; Methodology, P.T., V.R. and S.A.S.; Project administration, M.K.; Resources, G.S.; Software, G.S.; Supervision, G.S.; Validation, G.S.; Writing-Original draft, G.S.

Funding: This research received no external funding.

Conflicts of Interest: The authors declare no conflicts of interest.

\section{References}

1. Ansari, Z.; Miller, D.; Galor, A. Current thoughts in fungal keratitis: Diagnosis and treatment. Curr. Fungal Infect. Rep. 2013, 7, 209-218. [CrossRef] [PubMed]

2. Wong, T.Y.; Ng, T.P.; Fong, K.S.; Tan, D.T. Risk factors and clinical outcomes between fungal and bacterial keratitis: A comparative study. Eye Contact Lens 1997, 23, 275-281.

3. Leck, A.; Thomas, P.; Hagan, M.; Kaliamurthy, J.; Ackuaku, E.; John, M.; Newman, M.; Codjoe, F.; Opintan, J.; Kalavathy, C. Aetiology of suppurative corneal ulcers in Ghana and south India, and epidemiology of fungal keratitis. Br. J. Ophthalmol. 2002, 86, 1211-1215. [CrossRef] [PubMed]

4. Bharathi, M.J.; Ramakrishnan, R.; Meenakshi, R.; Padmavathy, S.; Shivakumar, C.; Srinivasan, M. Microbial keratitis in South India: Influence of risk factors, climate, and geographical variation. Ophthalmic Epidemiol. 2007, 14, 61-69. [CrossRef] [PubMed] 
5. Chowdhary, A.; Singh, K. Spectrum of fungal keratitis in North India. Cornea 2005, 24, 8-15. [CrossRef] [PubMed]

6. Gopinathan, U.; Sharma, S.; Garg, P.; Rao, G.N. Review of epidemiological features, microbiological diagnosis and treatment outcome of microbial keratitis: Experience of over a decade. Indian J. Ophthalmol. 2009, 57, 273-279.

7. Thomas, P.A. Current perspectives on ophthalmic mycoses. Clin. Microbiol. Rev. 2003, 16, 730-797. [CrossRef]

8. Srinivasan, M.; Gonzales, C.A.; George, C.; Cevallos, V.; Mascarenhas, J.M.; Asokan, B.; Wilkins, J.; Smolin, G.; Whitcher, J.P. Epidemiology and aetiological diagnosis of corneal ulceration in Madurai, south India. Br. J. Ophthalmol. 1997, 81, 965-971. [CrossRef]

9. Srinivasan, R.; Kanungo, R.; Goyal, J. Spectrum of oculomycosis in South India. Acta Ophthalmol. 1991, 69, 744-749. [CrossRef]

10. Manikandan, P.; Dóczi, I.; Kocsubé, S.; Varga, J.; Németh, T.M.; Antal, Z.; Vágvölgyi, C.; Bhaskar, M.; Kredics, L. Aspergillus species in human keratomycosis. In Aspergillus in the Genomic Era; Varga, J., Samson, R., Eds.; Wageningen Academic Publishers: Wageningen, The Netherlands, 2008; pp. 293-328.

11. Kredics, L.; Varga, J.; Kocsubé, S.; Dóczi, I.; Samson, R.A.; Rajaraman, R.; Narendran, V.; Bhaskar, M.; Vágvölgyi, C.; Manikandan, P. Case of keratitis caused by Aspergillus tamari. J. Clin. Microbiol. 2007, 45, 3464-3467. [CrossRef]

12. Manikandan, P.; Varga, J.; Kocsubé, S.; Samson, R.A.; Anita, R.; Revathi, R.; Dóczi, I.; Németh, T.M.; Narendran, V.; Vágvölgyi, C. Mycotic keratitis due to Aspergillus nomius. J. Clin. Microbiol. 2009, 47, 3382-3385. [CrossRef] [PubMed]

13. Kredics, L.; Varga, J.; Kocsubé, S.; Rajaraman, R.; Raghavan, A.; Dóczi, I.; Bhaskar, M.; Németh, T.M.; Antal, Z.; Venkatapathy, N. Infectious keratitis caused by Aspergillus tubingensis. Cornea 2009, 28, 951-954. [CrossRef] [PubMed]

14. Manikandan, P.; Varga, J.; Kocsubé, S.; Revathi, R.; Anita, R.; Dóczi, I.; Németh, T.M.; Narendran, V.; Vágvölgyi, C.; Bhaskar, M. Keratitis caused by the recently described new species Aspergillus brasiliensis: Two case reports. J. Med. Case Rep. 2010, 4, 68. [CrossRef] [PubMed]

15. Denning, D.W.; Venkateswarlu, K.; Oakley, K.L.; Anderson, M.; Manning, N.; Stevens, D.A.; Warnock, D.W.; Kelly, S.L. Itraconazole resistance in Aspergillus fumigatus. Antimicrob. Agents Chemother. 1997, 41, 1364-1368. [CrossRef]

16. Verweij, P.E.; Chowdhary, A.; Melchers, W.J.; Meis, J.F. Azole resistance in Aspergillus fumigatus: Can we retain the clinical use of mold-active antifungal azoles? Clin. Infect. Dis. 2016, 62, 362-368. [CrossRef] [PubMed]

17. Tanure, M.A.; Cohen, E.J.; Sudesh, S.; Rapuano, C.J.; Laibson, P.R. Spectrum of fungal keratitis at Wills Eye Hospital, Philadelphia, Pennsylvania. Cornea 2000, 19, 307-312. [CrossRef] [PubMed]

18. Clancy, C.J.; Yu, Y.C.; Lewin, A.; Nguyen, M.H. Inhibition of RNA synthesis as a therapeutic strategy against Aspergillus and Fusarium: Demonstration of in vitro synergy between rifabutin and amphotericin B. Antimicrob. Agents Chemother. 1998, 42, 509-513. [CrossRef] [PubMed]

19. Edwards, J.E.; Morrison, J.; Henderson, D.K.; Montgomerie, J.Z. Combined effect of amphotericin B and rifampin on Candida species. Antimicrob. Agents Chemother. 1980, 17, 484-487. [CrossRef] [PubMed]

20. Fujita, N.K.; Edwards, J.E. Combined in vitro effect of amphotericin B and rifampin on Cryptococcus neoformans. Antimicrob. Agents Chemother. 1981, 19, 196-198. [CrossRef] [PubMed]

21. Huppert, M.; Pappagianis, D.; Sun, S.H.; Gleason-Jordan, I.; Collins, M.S.; Vukovich, K.R. Effect of amphotericin B and rifampin against Coccidioides immitis in vitro and in vivo. Antimicrob. Agents Chemother. 1976, 9, 406-413. [CrossRef]

22. Kobayashi, G.S.; Cheung, S.C.; Schlessinger, D.; Medoff, G. Effects of rifamycin derivatives, alone and in combination with amphotericin B, against Histoplasma capsulatum. Antimicrob. Agents Chemother. 1974, 5, 16-18. [CrossRef] [PubMed]

23. Roeder, R.G. The role of general initiation factors in transcription by RNA polymerase II. Trends Biochem. Sci. 1996, 21, 327-335. [CrossRef]

24. Taylor, D. The pharmaceutical industry and the future of drug development. In Pharmaceuticals in the Environment; Hester, R.E., Harrison, R.M., Eds.; The Royal Society of Chemistry: London, UK, 2015; pp. 1-33. 
25. Josa, D.; da Cunha, E.F.F.; Ramalho, T.C.; Souza, T.C.S.; Caetano, M.S. Homology modeling of wild-type, D516V, and H526L Mycobacterium tuberculosis RNA polymerase and their molecular docking study with inhibitors. J. Biomol. Struct. Dyn. 2008, 25, 373-376. [CrossRef]

26. Rost, B. Twilight zone of protein sequence alignments. Protein Eng. 1999, 12, 85-94. [CrossRef] [PubMed]

27. Liithy, R.; Bowie, J.U.; Eisenberg, D. Assessment of protein models with three-dimensional profiles. Nature 1992, 356, 83-85. [CrossRef] [PubMed]

28. Pauling, L. The Nature of the Chemical Bond; Cornell University Pr.: Ithaca, NY, USA, 1948.

29. Sharma, O.P.; Pan, A.; Hoti, S.L.; Jadhav, A.; Kannan, M.; Mathur, P.P. Modeling, docking, simulation, and inhibitory activity of the benzimidazole analogue against $\beta$-tubulin protein from Brugia malayi for treating lymphatic filariasis. Med. Chem. Res. 2012, 21, 2415-2427. [CrossRef]

30. Shanmugam, G.; Lee, S.K.; Jeon, J. Identification of potential nematicidal compounds against the pine wood nematode, Bursaphelenchus xylophilus through an in silico approach. Molecules 2018, 23, 1828. [CrossRef]

31. Gopalakrishnan, S.B.; Kalaiarasi, T.; Subramanian, R. Comparative DFT study of phytochemical constituents of the fruits of Cucumis trigonus Roxb. and Cucumis sativus Linn. J. Comput. Methods Phys. 2014, 2014, 623235. [CrossRef]

32. Pruitt, K.D.; Tatusova, T.; Maglott, D.R. NCBI Reference sequence (RefSeq): A curated non-redundant sequence database of genomes, transcripts and proteins. Nucleic Acids Res. 2005, 33 (Suppl. 1), D501-D504.

33. Berman, H.M.; Westbrook, J.; Feng, Z.; Gilliland, G.; Bhat, T.N.; Weissig, H.; Shindyalov, I.N.; Bourne, P.E. The Protein Data Bank, 1999-, International Tables for Crystallography Volume F: Crystallography of Biological Macromolecules; Springer: Dordrecht, The Netherlands, 2006; pp. 675-684.

34. Spåhr, H.; Calero, G.; Bushnell, D.A.; Kornberg, R.D. Schizosacharomyces pombe RNA polymerase II at 3.6- $\AA$ resolution. Proc. Natl. Acad. Sci. USA 2009, 106, 9185-9190.

35. Šali, A.; Blundell, T.L. Comparative protein modelling by satisfaction of spatial restraints. J. Mol. Biol. 1993, 234, 779-815. [CrossRef] [PubMed]

36. Fiser, A.; Sali, A. Modeller: Generation and refinement of homology-based protein structure models. Methods Enzymol. 2003, 374, 461-491. [PubMed]

37. Scott, W.R.; Hünenberger, P.H.; Tironi, I.G.; Mark, A.E.; Billeter, S.R.; Fennen, J.; Torda, A.E.; Huber, T.; Krüger, P.; van Gunsteren, W.F. The GROMOS biomolecular simulation program package. J. Phys. Chem. A 1999, 103, 3596-3607. [CrossRef]

38. Kaplan, W.; Littlejohn, T.G. Swiss-PDB viewer (deep view). Brief. Bioinform. 2001, 2, 195-197. [CrossRef] [PubMed]

39. Laskowski, R.A.; MacArthur, M.W.; Moss, D.S.; Thornton, J.M. PROCHECK: A program to check the stereochemical quality of protein structures. J. Appl. Crystallogr. 1993, 26, 283-291. [CrossRef]

40. Eisenberg, D.; Lüthy, R.; Bowie, J.U. VERIFY3D: Assessment of protein models with three-dimensional profiles. Methods Enzymol. 1997, 277, 396-404. [PubMed]

41. Colovos, C.; Yeates, T. ERRAT: An empirical atom-based method for validating protein structures. Protein Sci. 1993, 2, 1511-1519. [CrossRef]

42. Volkamer, A.; Kuhn, D.; Rippmann, F.; Rarey, M. DoGSiteScorer: A web server for automatic binding site prediction, analysis and druggability assessment. Bioinformatics 2012, 28, 2074-2075. [CrossRef] [PubMed]

43. Kim, S.; Thiessen, P.A.; Bolton, E.E.; Chen, J.; Fu, G.; Gindulyte, A.; Han, L.; He, J.; He, S.; Shoemaker, B.A. PubChem substance and compound databases. Nucleic Acids Res. 2015, 44, D1202-D1213. [CrossRef] [PubMed]

44. Rarey, M.; Kramer, B.; Lengauer, T.; Klebe, G. A fast flexible docking method using an incremental construction algorithm. J. Mol. Biol. 1996, 261, 470-489. [CrossRef] [PubMed]

45. Gnanendra, S.; Mohamed, S.; Natarajan, J. Identification of potent inhibitors for Salmonella typhimurium quorum sensing via virtual screening and pharmacophore modeling. Comb. Chem. High Throughput Screen. 2013, 16, 826-839. [CrossRef] [PubMed]

46. Stierand, K.; Maa, P.C.; Rarey, M. Molecular complexes at a glance: Automated generation of two-dimensional complex diagrams. Bioinformatics 2006, 22, 1710-1716. [CrossRef] [PubMed] 
47. Kamakura, T.; Yamaguchi, S.; Saitoh, K.-I.; Teraoka, T.; Yamaguchi, I. A novel gene, CBP1, encoding a putative extracellular chitin-binding protein, may play an important role in the hydrophobic surface sensing of Magnaporthe grisea during appressorium differentiation. Mol. Plant Microbe Interact. 2002, 15, 437-444. [CrossRef] [PubMed]

48. Frisch, M.; Trucks, G.; Schlegel, H.; Scuseria, G.; Robb, M.; Cheeseman, J.; Scalmani, G.; Barone, V.; Mennucci, B.; Petersson, G. Gaussian 09, Revision A; Gaussian, Inc.: Wallingford, CT, USA, 2009.

(C) 2019 by the authors. Licensee MDPI, Basel, Switzerland. This article is an open access article distributed under the terms and conditions of the Creative Commons Attribution (CC BY) license (http://creativecommons.org/licenses/by/4.0/). 